post-endothelial tissue is known to occur, as in cases of congenital anterior synechiae and of imperfect differentiation of the angle. In these cases, however, the abnormally placed tissue usually resembled rather fluffy iris stroma and did not look like a hyaline reduplication of Descemet's membrane.

In conclusion one can only say that the condition is congenital and that it is in all probability due to an abnormality of the postendothelial tissue occurring at and after the $12 \mathrm{~mm}$. stage. The initial cause of the aberration and also the reason for its assumption of the peculiar appearance described must remain obscure, although the possibility of foetal inflammation acting as the initial cause must be admitted.

\title{
BIBLIOGRAPHY
}

1. Collins and Mayou.-Pathology of the Eye, p. 659, 1911.

2. Herbert, H.-Glass membrane formation in chronic iridocyclitis. Trans. Ophthal. Soc. U.K., Vol. XLVII, p. 155, 1927.

3. Ballantyne, A. J.-A case showing multiple congenital abnormalities. Proc. Roy. Soc. Med., Vol. XXVI, p. 13, 1933.

4. Stephenson, S-A curious congenital anomaly of the iris. Trans. Ophthal. Soc. U.K., Vol. XXVIII, p. 212, 1908.

5. Coats, G.-Researches on Congenital Anomalies of the Eyes. A case of Microphthalmos. Hunterian Lectures, 1910. The Ophthalmoscope, p. 693, 1910.

6. Mann, I.-The development of the cornea. Trans. Ophthal. Soc. U.K., Vol. LI, p. 63, 1931.

\section{HOLES IN THE "POSTERIOR HYALOID-MEMBRANE" OF THE VITREOUS-REPORT OF A CASE}

BY

\section{J. Ringland Anderson \\ MELBOURNE}

FEw circular central apertures in the vitreous have been reported in English ophthalmic literature. Therefore the following report is given.

The patient was a married woman, aged 30 years, who appeared to be exceptionally healthy, robust and free from septic foci. Her only illness had been a serious, though obscure, upset during the first few years of life. With a $+9 \mathrm{D}$. Sph. a delicate vertical membrane was visible in the left vitreous with a central aperture through which the optic disc could be clearly seen. This aperture was 1.5 disc diameters, but six months later it had definitely increased in size. Temporal to it there was a much larger circular hole which was tilted so that its nasal margin was seen with $+7.0 \mathrm{D}$. S. and 

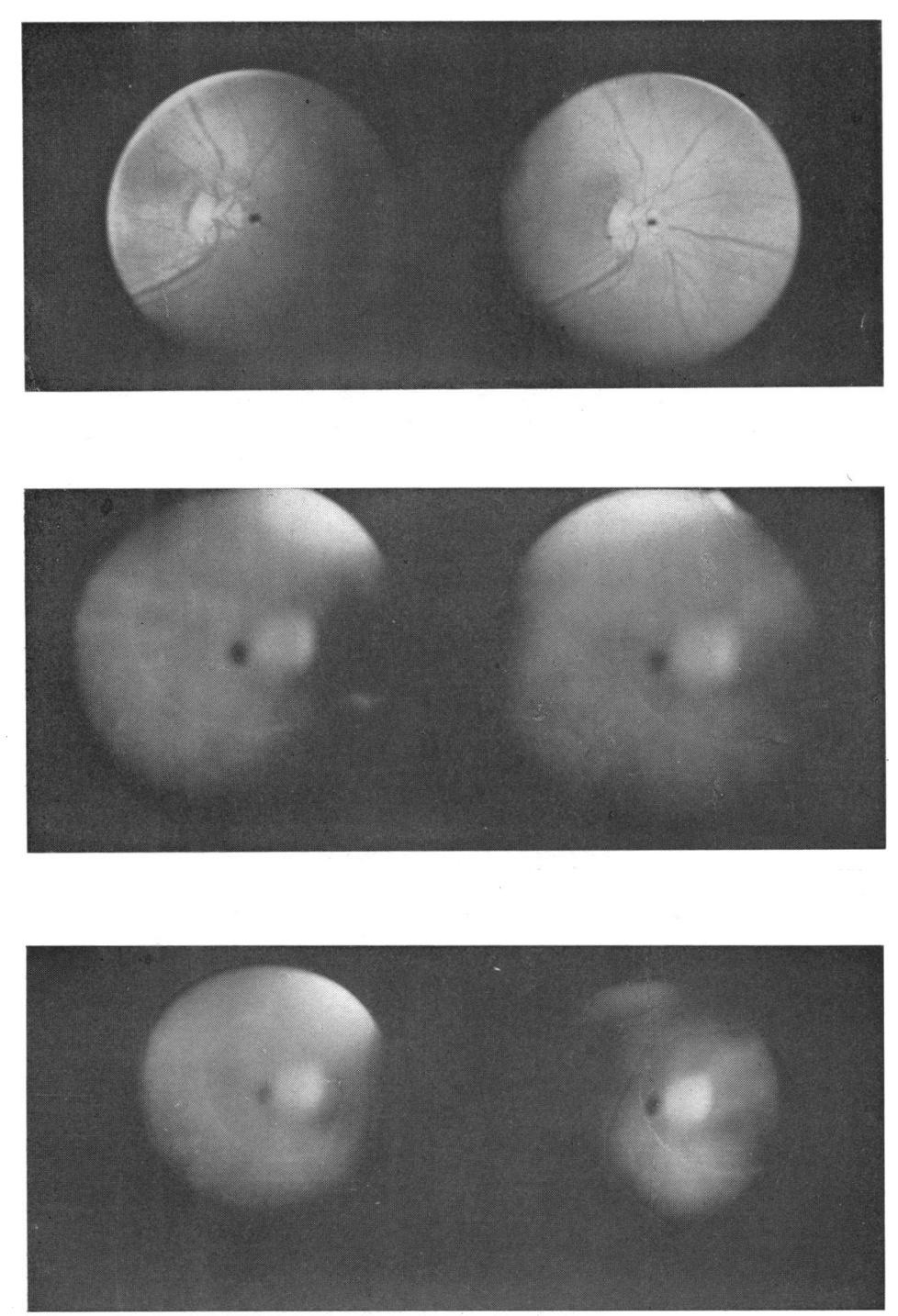

Stereophotographs of central hole in "posterior hyaloid" membrane of vitreous showing (1) central area of fundus. The membrane lay too far forwards to be in focus in this view, but it was sufficiently dense to blur the detail of the retinal vessels beyond the disc margins.

(2) and (3) show the margin of the hole and the blurred disc which is out of focus. The oval white area on one of these photographs is due to a light reflex on the strong convex sphere through which it was necessary to take these views to bring the anteriorly situated membrane into focus with the binocular fundus camera 


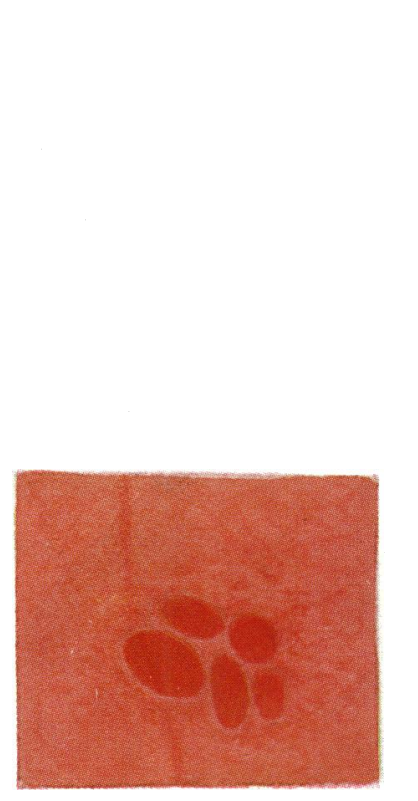

Plate 1.

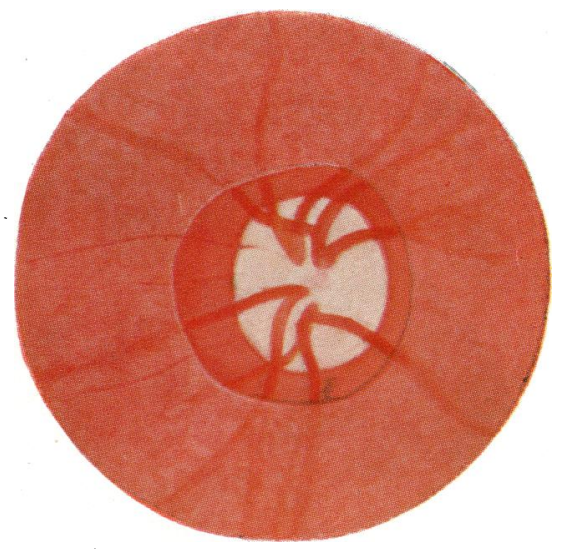

Plate 2.

Diagram to show the edge of the annular aperture in the thickened "hyaloid" membrane. The edge is illuminated by the slit-lamp beam.

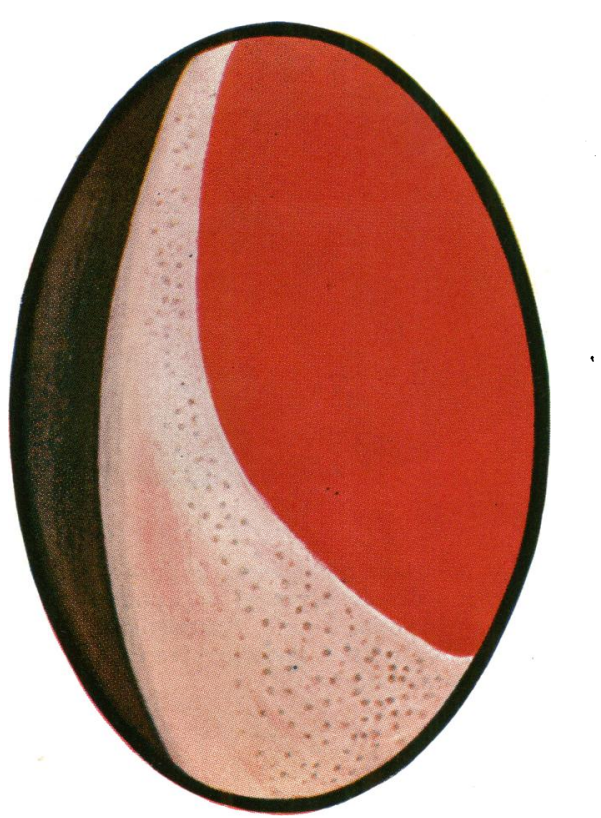

Plate 3. 


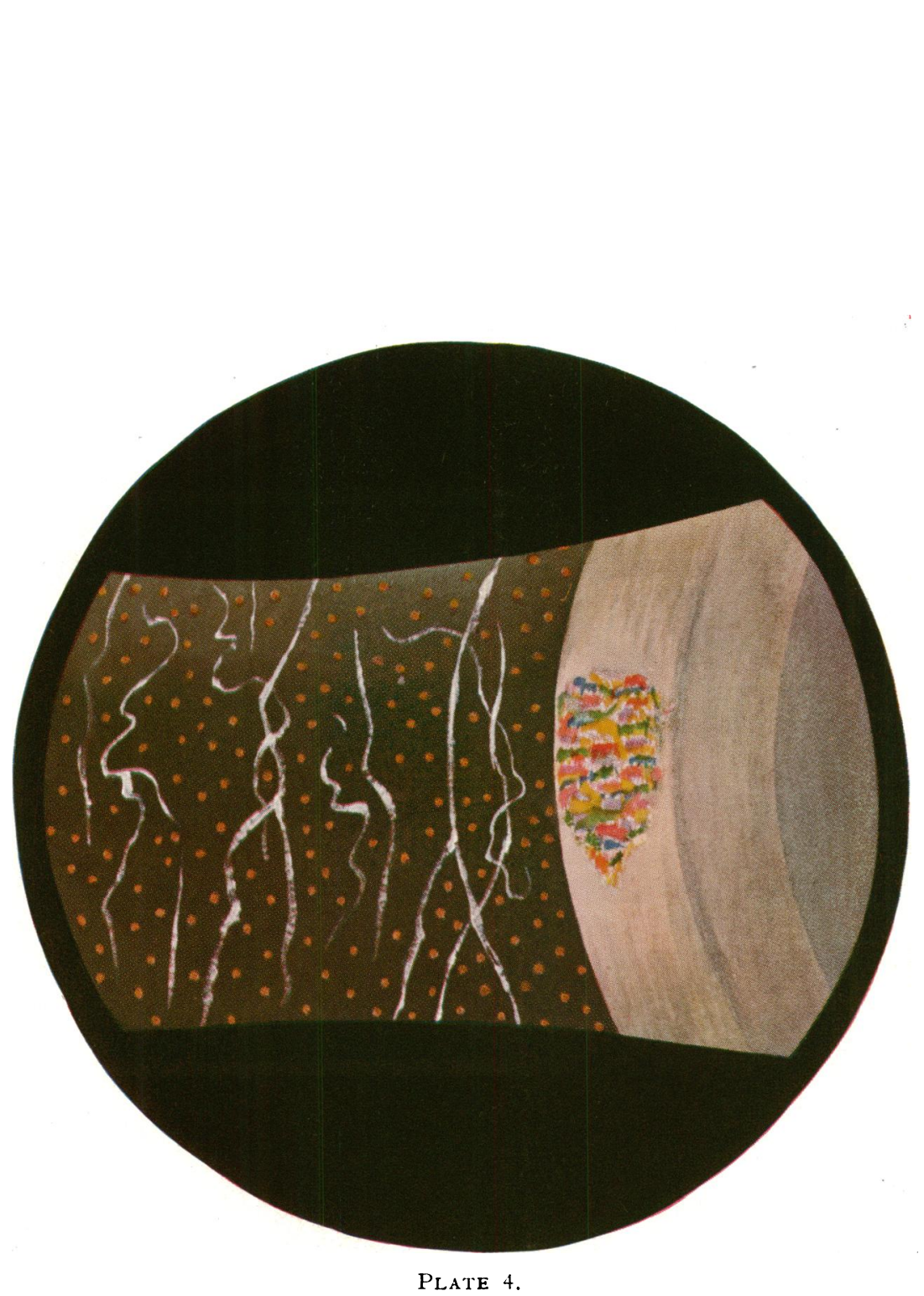

Posterior subcapsular iridescence of early complicated cataract as seen in Mrs. S's left eye. Numerous discrete posterior opacities were present as well as typical anterior axial embryonal dots. Numerous minute dot-like opacities are seen throughout the vitreous, the anterior framework of which shows partial destruction and filamentary bands. 
its temporal edge, which was almost in contact with the retina, was in focus with a $-4.0 \mathrm{D}$. Sph. In the temporal periphery lay several indistinct white retinal foci and in front of one of these and still partially connected with it lay a smaller annular opening, while towards the nasal periphery lay several clusters of smaller holes. (Plate 1). The vitreous was clear except for fine dust and this membrane which obscured the retinal vessels where not seen through apertures (Plate 2). Examination of the vitreous of the other eye was difficult owing to the presence of a secondary postcortical cataract, which had caused loss of vision during a period of 18 months, but it was possible to see, through the semi-opaque lens, a central aperture in the vitreous similar to that in the left eye. Biomicroscopy of the "hyaloid" membrane was difficult because of its posterior situation. It appeared to be situated one and a third lens diameters (antero-posterior) behind the posterior surface of the lens. The edge of the aperture was bright in direct illumination and the surface of the membrane was grey and covered with scattered spots (Plate 3). No structure was discernible within the aperture. This could be accounted for by transparence of the fluid lying between the membrane and the retina. Owing to the posterior situation of the membrane it could only be seen when the axes of the microscope and the slit-lamp almost coincided with the optical axis of the eye. If the axis of the incident light was more oblique, numerous fine white vitreous strands were seen as well as numerous dots lying immediately behind the lens. The lens of this eye showed typical iridescence and fine posterior cortical opacities (Plate 4). The lens of the other eye showed more advanced opacification and marked iridescence, and the cornea showed extensive endothelial bedewing.

\section{The Nature of the Membrane}

Two characteristics of vitreous that has prolapsed during an operation are well known. One is its tendency to remain in the wound without spreading as if held within a limiting membrane. If the prolapse is small it may even retract within the globe during the subsequent day or two. The second characteristic is a tendency to spread and become uncontrollable if either it is opened, or by increasing in quantity, it overcomes the controlling force. These observations have been used to support the theory that a "hyaloid" membrane surrounds the vitreous body. As no such membrane exists these features can be explained by the existence of a surface condensation similar to that which surrounds most gels. The ability of the vitreous to shrink and retract is probably due to its ability to give up its fluid content.

The vitreous membrane under consideration was more than a condensation. It was sufficiently opaque to blur one's view of 
fundus details. The existence of a delicate membrane resulting from some obscure degenerative or inflammatory lesion is suggested. The presence of vitreous dust and of early opacities in the lens of the same eye and of an advanced cataract in the other eye is further evidence of the existence of some morbid process. Probably the shrinkage of the vitreous had separated the membrane from the retina. Though the posterior surface of a detached vitreous tends to develop a cellular membrane, as does the retina when detached, yet the membrane in the case under consideration probably existed prior to the separation. Secondary membranes which form on the vitreous have been considered instrumental in the production of retinal tears. Possibly when the posterior limiting membrane is fragile at the time of its detachment, it separates in fragments which form floating opacities, rather than a thin layer with one or more apertures.

The central part of the membrane lay several millimetres in front of the retina. This finding suggests a marked shrinking forwards of the vitreous. It is well known that such a state, with complete liquefaction of the posterior half of the vitreous, is common in distended globes, in myopia and staphyloma, and in other conditions. Frequently the vitreous consists simply of a broad vertical band, running across the globe, attached only by its base near the circle of the ora serrata. The "white of egg" coagulation after cauterization is found much more frequently when the retinal hole lies close to the ora serrata than when it lies posteriorly. In the latter, the true vitreous is not touched and so no coagulation occurs. This proves the presence of posterior vitreous liquefaction. There is often a striking difference between the solid nature of the first bead of vitreous that escapes and the very fluid appearance of that which follows.

In 1885 Iwanoff described a single layer of endothelial cells on the inner surface of the retina in chronic retinitis. Since then much interest has been taken in such membranes. Collins and Mayou (1912) and Parsons (1905) describe this condition. It is conceivable that cyclitis or an anterior ocular inflammatory condition could produce such a change. Such membranes have rarely been observed ophthalmoscopically. If one detached with the vitreous it might resemble that seen in the case under consideration. The nature of epi-retinal and particularly epi-papillary membranes has recently been discussed by Samuels (1931).

\section{The Genesis of Apertures}

When a vitreous body becomes detached from the membrana limitans interna retinae it may remain attached to either the optic disc, some old inflammatory retinal focus or a scar from an old 
injury. When the posterior limiting membrane of the vitreous separates from the margin of the disc, it tears away from the wide funnel-shaped expansion of Cloquet's canal, Martegiani's area. If a so-called hyaloid membrane separates from such points of attachment a series of holes may become visible. Similarly, after a cataract extraction, an anterior rounded aperture may be found which exposes an area of clear primary vitreous or one that is clear because of liquefaction.

Baenziger in 1891 and Vogt and Stahli, more recently, have reported a central aperture, due to separation of the vitreous from the optic disc, as a relatively common finding in myopia and senility. It has been found during slit-lamp examination of the fundus by Koeppe's method and by indirect arc lamp ophthalmoscopy, with a plane mirror. Vogt (1924) classes this prepapillary ring-shaped opacity as one of the most frequent vitreous opacities of the senium and of myopes. Its development is accompanied by photopsiae, which last as a rule only for a few days, and by the appearance of a more permanent ring which after some months alters in form and position. Vogt considers this ring to be just as characteristic of the senium as circum- and prepapillary atrophy, and posterior cortical lens opacities, etc., are. The ring hovers at a variable distance in front of the optic disc and sometimes, when seen from the side, it will appear oval though somewhat distorted. Such a ring probably plays no part in the evolution of a spontaneous retinal detachment. The development of this aperture necessitates a more or less complete release of the posterior vitreous by the retina which may be a substitute for relinal detachment. Though Vogt considered that the separation of such a membrane and the formation of a central aperture probably played no part in the evolution of a spontaneous retinal detachment, yet recently (1932), he has described an elderly myope who developed a total detachment and an extensive paramacular hole (5 disc diameters $\times 2$ disc diameters) some years after the sudden onset of a vitreous detachment. It is interesting to note that though it was necessary to cauterize $22 \mathrm{~mm}$. from the limbus yet the retina completely reattached.

Vitreous detachment is a condition not always recognized, probably because of the vitreous opacities which accompany it. Sudden movement or prolonged strain or contraction of vitreous bands may cause detachment of the vitreous or even of the retina.

Lister describes variations in the appearance of the posterior limiting layer in vitreous detachment. It may be shaggy, blurry and indefinite or quite clearly defined. In other cases it may be thrown into delicate folds. Injury, inflammation or haemorrhage may produce localized attachments between the vitreous and the retina. Most frequently however such attachments are due to the 
scattered foci of chorio-retinitis, a characteristic of myopic and senile eyes. These may exert tension on both tissues and produce photopsiae. If the vitreous becomes detached, a tear in the posterior limiting layer results, or, if the retina is also adherent to the choroid, a retinal tear may form. The adherent retinal tissue may remain attached to the vitreous and produce a tear with a lid (Plates 5 and 6 ) or it may adhere to the choroid and a circular hole without a lid be produced.

Lister (1922) stated that he had seen one central vitreous hole and two that were due to the hyaloid membrane having torn its mooring from a patch of retino-choroidal atrophy. Most of the reported apertures of this kind have been associated with an unusually dense posterior limiting layer. This makes the margin of the hole easier to find and enables it to maintain its circular shape.

Rea (1923), Gimblett (1923) and Bedell (1925) each describe an annular opening in the posterior "hyaloid membrane." In the vitreous described by Goldstein (1923) an almost circular hole and a patch of chorio-retinal atrophy of corresponding size were seen. Purtscher's patient (1919) showed a similar appearance. Kraupa has seen tears in the periphery of the vitreous with an arc-lamp. Isakowitz (1926) reported an example of a "hyaloid" hole associc ted with a small retinal detachment. It appeared as if contraction in the neighbourhood of the macula had produced the tear. 'The membrane around the hole obscured the vessels and was approximately $2 \mathrm{~mm}$. in front of them. The detachment, however, was not typical of the spontaneous type, and was associated with vascular degeneration and haemorrhages.

Bilateral senile vitreous rings were reported by Isakowitz (1932). The patient, an emmetrope, aged 57 years, had observed a ringshaped shadow before one eye for nine months and before the other for three months. The opacities could be clearly focussed with +8.0 D. Sph. to +10.0 D. Sph. lenses.

Kraupa $(1919,1923,1924,1925)$ has studied the origin of such ring-shaped holes and the development of typical vitreous opacities of myopia from the remnants of the posterior limiting layer. In one of his patients this layer was torn from a large choroidal lesion. Later, as it separated from the optic disc, two holes developed in it. As the perforated layer was slightly detached and thickened it tended to obscure the retinal vessels. When separation was complete a short cord remained adherent to the vessel entrance in the disc and two holes appeared in the vitreous like the circular rims of a spectacle frame. They later merged into one.

There is little that one can confuse with a central annular opening in the vitreous. It is unlike all other vitreous opacities and the vestigial remnants associated with Cloquet's canal. If the ring is tilted and seen in profile it may be more difficult to recognize. The 


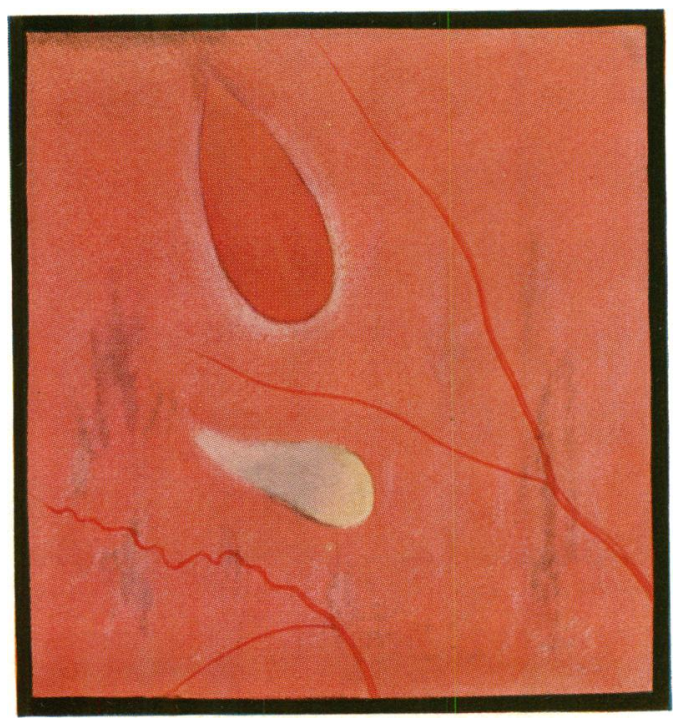

Plate 5.

Pear-shaped retinal hole in the superior temporal quadrant of a nonmyopic female patient aged 60 years. Immediately below and at a slightly anterior level lies an elongated retino-vitreous adhesion. This is opaque and appears yellow when seen in the convergent beam of the ophthalmoscope. It is assumed that it once formed the lid of the retinal hole. Such an opacity is at times a guide to the site of a hole. After the patient had been recumbent for two days this adhesion was found to be closer to the tear which had become more slit-like. 

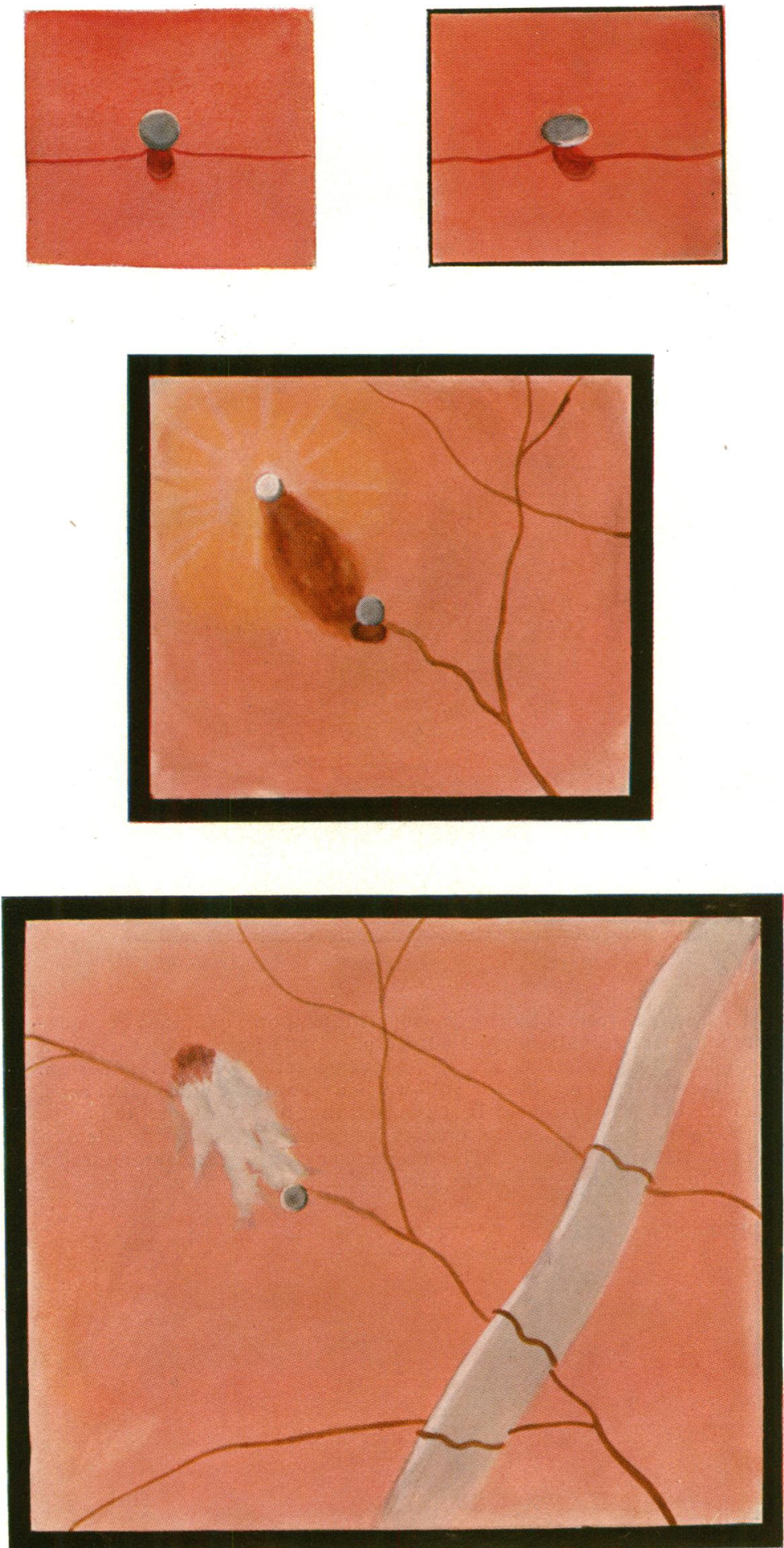

Plate 6.

Mr. L. Round hole below retino-vitreous adhesion, a tear with " a lid." 1. Erect posture. 2. Recumbent posture. 3. After scleral puncture and insertion of scleral stud. 4. After two seconds cauterization. 
ring is never smaller than one disc diameter and is usually two or three times as large. One is struck by the marked parallax that exists between the margins of this opening and the optic disc. This results from the extreme displacement forwards of this ring. It may be in focus with a lens in the ophthalmoscope that is 17 D. Sph. more convex than that which brings the disc details into focus.

Not uncommonly one finds an irregular ring-shaped opacity in a degenerate vitreous. Such an opacity may be seen by the patient as a ring and at times it is possible for him to make a sketch of this opacity. Probably these opacities are late forms of the opacity described in this paper. They certainly are coarser and more irregular.

Amsler's experimental researches (1930) based on measurements of the reflex by photography, showed the annular opacity to be $6 \mathrm{~mm}$. in front of the optic disc. One of his patients was able to draw the round window through which she appeared to be looking. Another, a doctor of medicine, who had had a retinal detachment for two months, described how, 12 days before the sudden appearance of a dark curtain, a diffuse mist developed, in the centre of which was "un noeud de chirurgien mal noué," a badly-tied surgeon's knot, the interior of which was clearer than the surroundings. In two of Amsler's cases retinal detachment appeared to follow separation of the posterior hyaloid. In one of these the ring was tilted and so appeared oval. These two tears appeared to be from 1 to $2 \mathrm{~mm}$. in front of the optic disc. Amsler's most interesting observations were those relating to the alterations in shape and position of such rings after cauterization for retinal detachment. Before operation they were concentric with the ora serrata and afterwards they were elongated and drawn towards the scar. In one case the ring appeared to be displaced 4 disc diameters from its original site.

\section{Summary}

1. A report is made of a healthy patient with various apertures in a vertical membrane situated in each vitreous. They were associated with cataracta complicata and fine retino-choroidal changes.

2. Reference is made to similar central apertures in myopia and the senium and to eccentric and more irregular openings after retino-choroidal disease.

3. As a sequel to some pre-existent morbid process the vitreous shrinks and becomes detached from the retina. This separation may tear a thickened posterior limiting membrane which is a product 
of disease and may become thicker when detached. Through such a tear clear fluid passes to fill the space behind the vitreous. The membrane may contract and form opacities which float in the degenerate vitreous. It may, by tearing the retina, play some part in the evolution of one type of retinal detachment.

\section{REFERENCES}

1905. Parsons.-Pathology of the Eye. Pp. 429 and 573, figs. 415, 416, 418.

1912. Collins and Mayou.-Pathology and Bacteriology of the Eye. P. 337.

1919. Purtscher, A.-Zeitschr. f. Augenheilk., Vol. XLII, p. 256.

1922. Lister, W.-Amer. Jl. of Ophthal.. Vol. V, p. 488.

1923. Rea, L.-Proc. Roy. Soc. Med., London, January 20.

1923. Gimblett, C.-Proc. Roy. Soc. Med., London, January 20.

1923. Goldstein, I.-A rch. of Ophthal., Vol. LII, p. 271.

1923- Kraupa, E. K.-Klin. Monatsbl. f. Augenheilk., Vol. LXX, p. 716 ; Vol. 25. LXX, p. 476; Vol. LXXV, p. 708.

1924. Vogt, A.-Klin. Monatsbl. f. Augenheilk., Vol. LXXII, p. 212.

1925. Bedell, A. J.-Trans. Ophthal. Soc. U.K., Vol. XLV, p. 656.

1926. Isakowitz, J.-Klin. Monatsbl. f. Augenheilk., Vol. LXXVII, p. 121.

1930. Amsler, M.-Bull. et Mem. Soc. frang. d'Ophtal., Vol. XLIII, p. 315.

1931. Samuels, B.-Arch. of Ophthal., November 6, p. 704, figs. 11 and 12.

1932. Vogt, A.-Klin. Monatsbl.f. Augenheilk., Vol. LXXXIX, p. 261.

1932. Isakowitz, J.-Klin. Monatsbl. f. Augenheilk., Vol. LXXXVIII, p. 369.

\section{DISLOCATION OF THE RING OF SOEMMERING,} ITS REMOVAL. WITH SOME NOTES ON ITS PATHOLOGY*

BY

FREDERICK TOOKE

MONTREAL, CANADA

THE Ring of Soemmering may briefly be defined as the capsular remains of a cataractous lens containing, as is usually the case, some retained cortical cells, the centre of the lens having been penetrated and an aperture created by some intentional operative procedure; or possibly by a penetrating wound of unintentional or accidental character. It can readily be detected, in some cases naturally more clearly than in others, in the average aphakic eye where the lens has not been removed in its capsule. A very beautiful example of the Ring in situ is seen in a specimen supplied me by Dr. MacMillan, showing it held in suspension by the zonule of Zinn, and demonstrating certain pathological features common to the retained capsule as a rule, but peculiar to the case to which I am presently to refer (Fig. 2).

\footnotetext{
* Read before the American Ophthalmological Society, Washington, D.C.
} 